\title{
Many hands make light work of climate study
}

\section{'Massively parallel' computers used - Improved accuracy achieved}

\section{Washington}

US researchers studying global change, frustrated by a shortage of computer time with which to run their huge and complex climate models, are turning to experimental, 'massively parallel', supercomputers as an alternative to expensive and heavily used traditional supercomputers such as those made by Cray Research.

A draft plan completed last week by the US Department of Energy (DOE) outlines a 10 -year, \$240-million plus programme to adapt climate change models to massively parallel computers. Known as the Computer Hardware, Advanced Mathematics and Model Physics (CHAMMP) initiative, the project is subtitled "a DOE program for climate change". DOE has asked Congress for $\$ 8$ million in 1991 for the initiative.

Three US national laboratories have already started trying to convert existing climate change models to run on massively parallel machines. The parallel architectures of the new supercomputers allow them to carry out many simple tasks simultaneously, a feature that may apply well to climate models where the global climate is divided into hundreds or thousands of continuously changing cells.

Los Alamos and Oak Ridge National Laboratories are working on adapting atmospheric models, while the Lawrence Livermore National Laboratory will initially concentrate on the more complicated ocean models.

CHAMMP's eventual goal is to improve performance in climate change models by a factor of 10,000 relative to a single-processor Cray II. According to the draft CHAMMP report, a factor of 100 can arise directly from the switch to parallelism, a factor of ten can be achieved by fine-tuning the models' algorithms and another factor of ten should arise as compilers for parallel machines improve.

Massively parallel machines (sometimes known as 'hypercubes') may even be able to run typical climate change models a thousand times faster than an 8processor Cray Y-MP - now the state of the art - within the next ten years, DOE researchers say.

By the end of the year, the DOE hopes to have equalled a Cray X-MP in running a standard atmospheric model designed by the National Center for Atmospheric Research (NCAR). The NCAR model is designed to run without modification on Cray 'moderately parallel' supercomputers, which have up to 64 processors.
Because the NCAR model is already designed with some parallel operation in mind, converting it to run on machines with hundreds or thousands of processors should provide a relatively straightforward test of massive parallelism in climate modelling.

Robert Chervin, who heads the NCAR team, describes the processor competition as "few-but-powerful versus many-butweak". In contrast to the hand-wired Crays, which have a small number of extremely powerful and complex processors, the massively parallel machines string together hundreds of cheap off-theshelf processors such as those found in desktop personal computers.

Initially, says Lawrence Livermore physicist Cecil Leith, "the main thing is to be cost-effective". Although today's massively parallel machines may not be as fast as a Cray at running climate models, they are many times cheaper, he says. One of the constant complaints of climate change researchers is the difficulty of finding enough computer time to run their models. Cheaper supercomputers should bring more power to all.

In congressional testimony last week, University of Illinois atmospheric scientist Michael Schlesinger told the House of Representatives sub-committee on science, research and technology that only one atmospheric research facility in the world - the West German Max Planck laboratory - has a dedicated supercomputer for climate modelling, although the UK Meteorological Office will soon be acquiring one as well. "Our hands have been tied. I can't think of another instance where the imbalance [between supply and demand] is as severe", he complained.

Present climate models divide the world into cells that measure $500 \mathrm{~km}$ on a side. Many scientists believe that it will be necessary to move to a higher resolution before basic questions about global warming can be answered. But a climate model with $50-\mathrm{km}$ cells would take 40 years to run, Schlesinger said. Moving the models to massively parallel machines could be the answer. "The bang for the buck will be enormous if we can make it work", he said.

The largest hurdle so far in running climate models on massively parallel supercomputers is what Oak Ridge researcher Robert Ward calls "the load balance problem". "In one region you may be modeling a storm while in another part of the country you're modeling a

\section{The party continues ...}

\section{Washington}

DESPITE the urging of a recent Department of Energy (DOE) panel against "any special funding" of cold fusion research, the department plans to double its budget next year for work in this field.

DOE will spend slightly more than $\$ 1$ million this year on five researchers who are studying cold fusion phenomena, according to Ryszard Gajewski, director of DOE's advanced energy projects programme. But because of continuing interest in the community, Gajewski says that amount is expected to increase to “about \$2 million” in the 1991 fiscal year, which starts in October; "there is highquality basic research to be done".

"What we would like to see are carefully designed controlled experiments that would answer the question of whether these phenomena are really there. I have a completely open mind about which way it will be resolved." Late last year, an advisory panel convened by the DOE Energy Research Advisory Board concluded that experimental results had not presented "convincing evidence" that useful sources of energy would result from cold fusion phenomena. But although the panel recommended against the establishment of special programmes or centres, it was "sympathetic towards modest support" for cooperative experiments within the existing DOE funding system.

"We are following the recommendations of the panel", says Gajewski. New awards will go to cooperative research between "those who have seen effects and those who have not seen effects", he says.

Other current cold fusion funding sources include the state of Utah, which last year set aside $\$ 5$ million for the creation of a cold fusion centre around the work of Stanley Pons and Martin Fleischmann. And in June 1989, the Office of Naval Research also awarded Pons a $\$ 400,839$, two-and-a-half-year grant, of which more than $\$ 240,000$ remains to be spent.

G. Christopher Anderson

sunny day. You have to worry about keeping all the processors busy", he says. There may be a limit to how simple and numerous the individual processors in a parallel machine for climate models can be, he says.

NCAR's Chervin also warns that faster computers may not guarantee accurate models. "Some of the [scientific] issues cannot be beaten to death with more [computer] cycles. There's a major difference between scientific computing and computer science." The effect of clouds, water vapour and the oceanic absorption of carbon dioxide are issues that still resist accurate theory, no matter how much computer power is applied, he says.

G. Christopher Anderson 